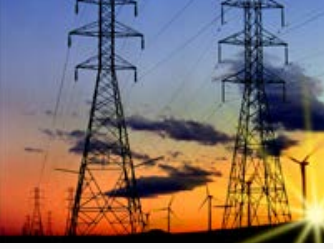

\title{
ENERGY SYSTEMS INTEGRATION *
}

ESI optimizes the design and performance of electrical, thermal, fuel, and water pathways at all scales.

\section{ESIF Plugs Utility-Scale Hardware into Simulated Grids to Assess Integration Effects}

At NREL's Energy Systems Integration Facility (ESIF), integrated, megawattscale power hardware-in-the-loop (PHIL) capability allows researchers and manufacturers to test new energy technologies at full power in real-time simulations-safely evaluating component and system performance and reliability before going to market.

Hardware-in-the-loop simulation is not a new concept, but adding the unique, megawatt-scale power capacity of the ESIF takes energy systems integration research to another level. Hardwarein-the-loop simulation seamlessly integrates physical hardware and software models in a single closed-loop simulation — and PHIL does this at full power. By using software to simulate the actual electric distribution circuit, PHIL testing ensures new, innovative hardware works with the utility system at actual load levels before it is integrated in the system. Researchers can mirror real-world conditions and evaluate complex interconnection scenarios, all while in a controlled laboratory setting - posing no risk to electric utilities or their customers.

Manufacturers can use this capability at the ESIF to test advanced device controls and functionality and verify their efficacy and reliability at full power - and determine whether their integration changes the landscape of the utility system. With this knowledge, manufacturers learn how to design their technologies to seamlessly integrate with the system, and utilities and investors gain the confidence to support integrating them-helping us move toward wide-scale clean energy deployment.

\section{How PHIL Simulation Works}

At the ESIF, PHIL simulation places hardware systems and software models together to test components at full power. In this diagram, a solar photovoltaic (PV) inverter-which converts the direct current (DC) power produced by a PV array into usable alternating current (AC) electricity for the grid - is the hardware under test in a PHIL simulation. A software model simulates the electric distribution circuit, and the hardware connects to a particular point — often referred to as the point of common coupling (PCC) - in this circuit. A real-time simulator runs the software model and the communication interface between the software and hardware.
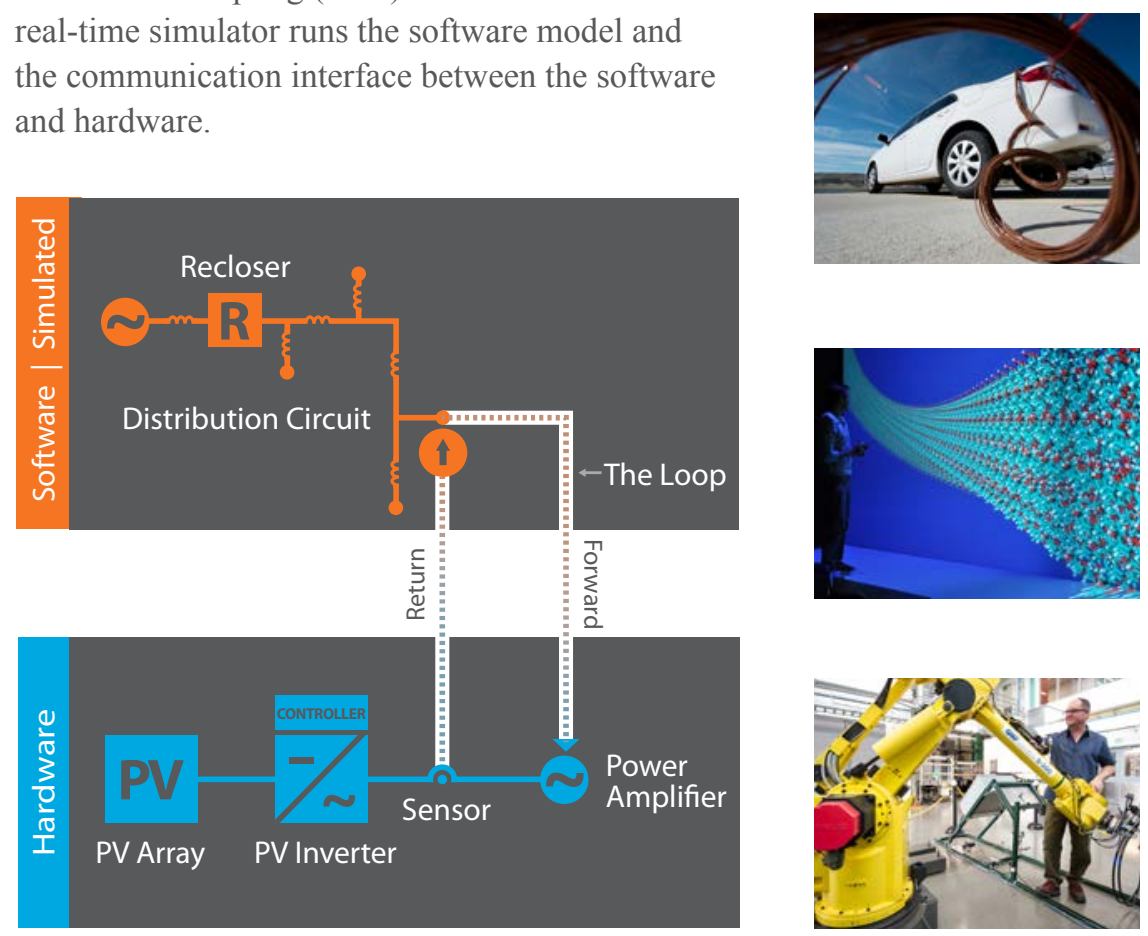

The PV inverter receives DC power input from a (real or simulated) PV array, and converts it into AC electricity. This AC output is absorbed by the power amplifier (which models the physical PCC that the inverter would connect to in the field), measured via a current sensor, and converted to a digital value. This current value is then injected into the simulated distribution circuit at the PCC. This current injection will cause changes in voltages and
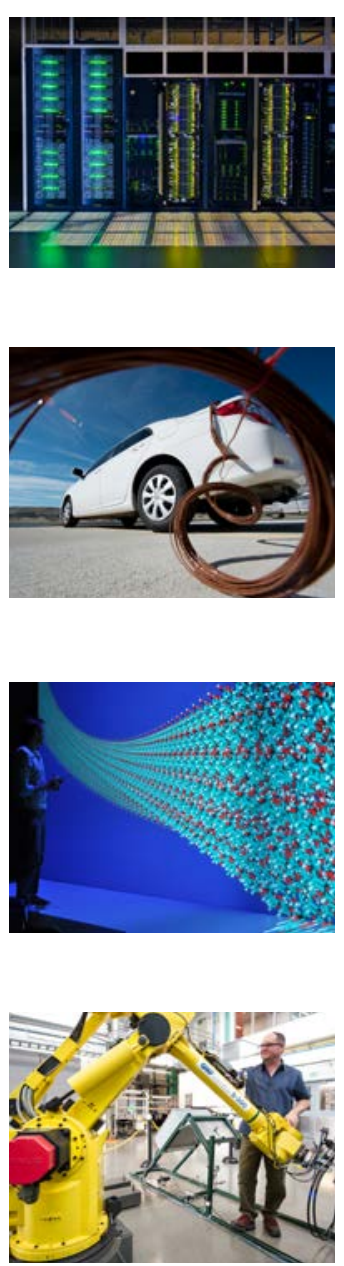

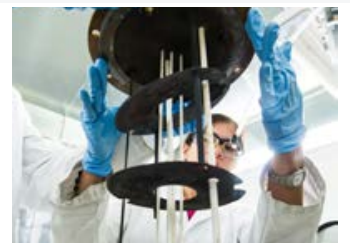




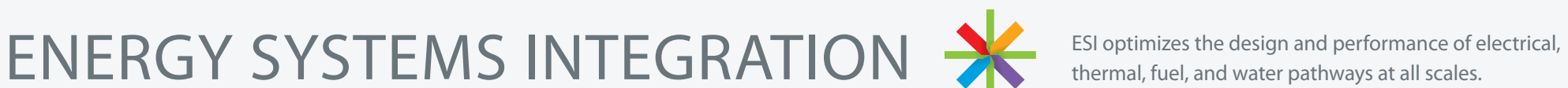

currents in the distribution circuit model, which will in turn cause a response from the distribution model and its integral components - such as modeled homes, buildings, or utility voltage regulation devices. The model's resulting PCC voltage is then converted from its digital value and transmitted as a voltage command to the power amplifier.

Tests using PHIL are easily repeatable, and the simulation is extremely flexible. Other "plug-and-play" elements-whether they be electric, thermal, fuels, or data components - can be added and subtracted at different points in the simulation loop to show their separate and integrated effects. Multiple simulations can occur simultaneously, in real time - so countless interconnection scenarios can be evaluated. Power hardware-in-the-loop can even model sophisticated communications between devices within a simulated system.

\section{PHIL at Play: Advanced Energy Tests Inverter at the ESIF}

Industry has already begun to take advantage of the ESIF's PHIL capability. In 2013, NREL researchers worked with industry partner Advanced Energy to complete preliminary testing of its 500-kilowatt PV inverter's advanced grid support features. This year, NREL researchers plan to take this work to the next level by testing the same inverter when connected to a simulated real-world electric distribution system using PHIL techniques. This will allow for evaluation of the inverter's advanced features and their impact on an electric distribution system prior to field deployment on an actual distribution system.

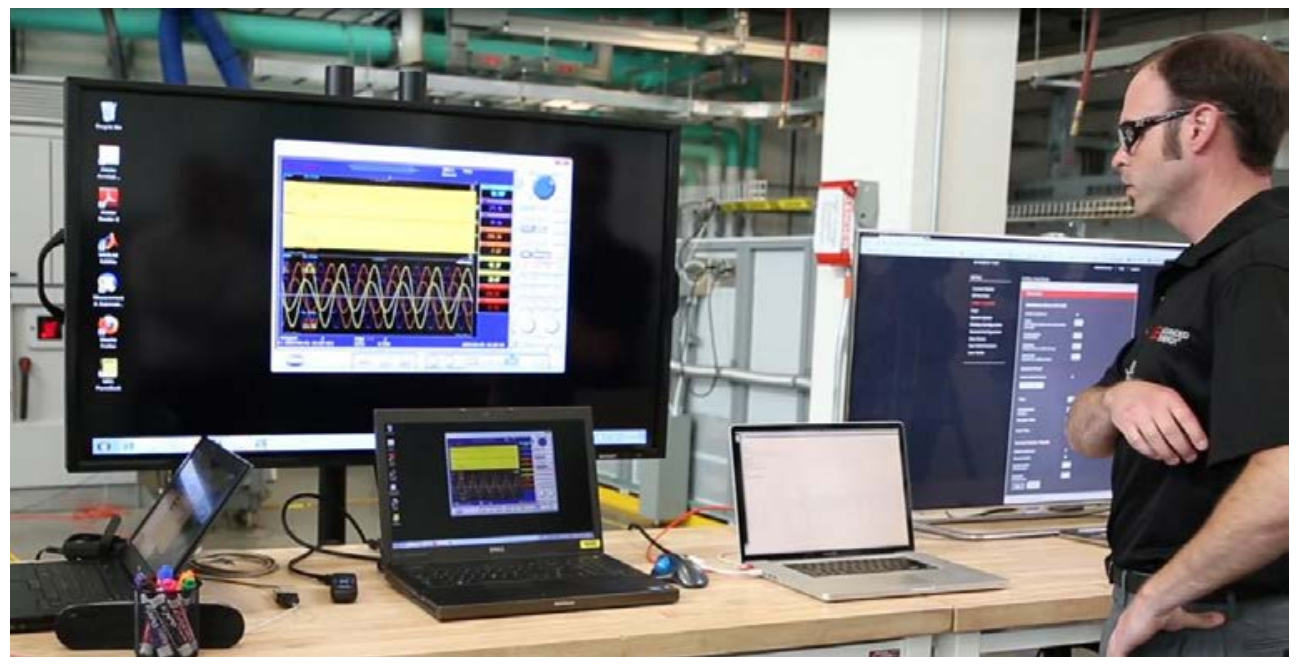

Testing of Advanced Energy's 500-kilowatt inverter at the ESIF. Still from U.S. Department of Energy video

Ultimately, this kind of testing will bridge the gap from current levels of solar grid integration to high penetration deployment by giving utilities the confidence that this advanced hardware not only functions as intended - but also provides added benefit to the grid. NREL's work with Advanced Energy is just one example of how industry is leveraging the unique capabilities of the ESIF to test new hardware and make sure that it all works together in tomorrow's grid of the future.

\section{Partner With Us}

Manufacturers, utilities, microgrid operators, and other research organizations can partner with NREL to take advantage of the ESIF's unique PHIL capability. Visit www.nrel.gov/esi/working_with.html for more information.

\section{Making the Connection: The Research Electrical Distribution Bus}

Central to the ESIF's "plug-and-play" PHIL capability is the Research Electrical Distribution Bus (REDB), the electrical backbone that interconnects many of the ESIF laboratories. The REDB functions as a power integration circuit capable of utilizing multiple AC and DC buses that connect multiple sources of energy, interconnecting laboratories and experiments to test and simulate equipment.

National Renewable Energy Laboratory 15013 Denver West Parkway

Golden, CO 80401

303-275-3000 • www.nrel.gov

NREL is a national laboratory of the U.S. Department of Energy, Office of Energy Efficiency and Renewable Energy, operated by the Alliance for Sustainable Energy, LLC.

NREL/FS-5B00-61260 • April 2014

Front page photography (from the top): photo Illustration by Raymond David, NREL 19498; Dennis Schroeder, NREL 26586; Dennis Schroeder, NREL 24358-C; Dennis Schroeder, NREL 19931; Kenny Gruchalla, NREL 25944; Dennis Schroeder, NREL 28858

Printed with a renewable-source ink on paper containing at least $50 \%$ wastepaper, including $10 \%$ post consumer waste. 